\title{
Telehuman Services Improves the Engagement of Low-Income Populations
}

\author{
Yolandra A. Plummer \\ University of the District of Columbia \\ Department of Management
}

Received: Jun. 23, $2021 \quad$ Accepted: Aug. 2, $2021 \quad$ Online published: Aug. 20, 2021

doi:10.5296/jpag.v11i3.18789 URL: https://doi.org/10.5296/jpag.v11i3.18789

\begin{abstract}
The paper describes a range of evidence-informed strategies that a Historically Black, Colleges and University (HBCU) work readiness program adopted to increase the engagement of Temporary Assistance for Needy Families (TANF) program participants during the COVID-19 pandemic. The program successfully engaged half of the program participants through two-generational (2Gen) approach. The 2Gen approaches target low-income children and parents from the same household and combine parent and child interventions to interrupt the cycle of poverty. These approaches emphasize early childhood education, economic supports, postsecondary education, social capital and health and well-being to create a legacy of economic security. The paper highlights the human services delivery strategies utilized to engage individuals into work readiness training activities during the pandemic. The paper presents data where certain $2 \mathrm{Gen}$ activities engaged TANF participants more than other $2 \mathrm{Gen}$ activities. The data reveals that half of the participants completed online digital literacy courses and earned training certifications. The intent of the paper is to offer state and local human service agency policymakers' guidance on strategies to increase TANF participant engagement.
\end{abstract}

Keywords: TANF engagement, Two-generation (2Gen), Work-readiness, HBCU, COVID-19

\section{Introduction}

The Temporary Assistance for Needy Families (TANF) block grant provides grants to states, territories and American Indian tribes to finance a wide range of benefits and services for needy families with children. The intent is to ameliorate the effects of economic disadvantage among families with children (Falk and Landers, 2021). The TANF program is more commonly recognized for providing government economic assistance to families and children. 
The U.S. Department of Health and Human Services (DHHS) funds the TANF program. Other funded services include childcare, employment and training programs and other social services. Eligible parents are required to complete work and/or activity participation requirements. At the onset of the Coronavirus Disease (COVID-19) pandemic, DHHS modified the work participation requirements in order that participants could focus on the health and safety of their families (Carter, 2020).

As the United States of America faced a national public health and economic emergency, the federal agency granted reasonable cause exceptions to participants that would have faced a penalty for failing to meet the work participation rates due to the COVID-19 emergency. A reasonable cause exception meant that the participant would not incur a financial penalty (OFA Publishes Guidance on the Implications of the COVID-19 Pandemic for the TANF Program, 2020)

Examples of the flexibility and good cause exemptions from work requirements included:

-The participant was ill, caring for a child because of daycare and/or school closures due to the pandemic or worksite and/or training site was closed.

-TANF programs could provide online and/or virtual/remote approaches for participants to engage in work activities virtually. This included online trainings, job search and work readiness programs to encourage and sustain participant engagement; and

-Case Managers were able to perform case management by telephone and other virtual platforms.

\section{Statement of the Problem}

Prior to the COVID-19 pandemic, the District of Columbia provided services to District residents receiving TANF benefits through its TANF Employment Provider (TEP) program. The TEP programs provided coaching towards education and employment goals. The District of Columbia continued to support TANF participants during the pandemic. This included laptops needed for remote participation.

The TEP programs were responsible for coaching TANF participants to shift their focus to the family's well-being. Once the pandemic began, TEP programs were encouraged to identify strategies to engage TANF participants in health and wellness, early childhood education, postsecondary education, peer network and financial literacy activities. Previously these activities were performed face-to-face. During the pandemic, TANF participants needed to learn how to become engaged using virtual platforms.

\section{Relevant Scholarship}

The current research on the TANF populations focuses on the government's guidance on work participation rates during the COVID-19 crisis and program instruction on providing case management by telephone and/or other virtual/electronic communication platform (OFA Publishes Guidance on the Implications of the COVID-19 Pandemic for the TANF Program, 
2020). Research from Benton et. al (2021) examines populations who are best served through virtual services (Benton et al, 2021).

Research from Meyer and Pavetti (2021) documents rigorous evaluations that have demonstrated that well-designed and well-implemented subsidized employment, education, or training programs that focus on building skills and providing adequate support to ensure success can increase the employment and earnings of TANF participants (2021).

This research aims to augment the current body of research on work readiness programs for individuals receiving TANF benefits. This research is an early effort to continue to document preliminary lessons learned by a HBCU to engage traditionally underserved and marginalized populations in work readiness training. It is also an opportunity to identify opportunity gaps between policymakers and communities to embrace collaborative approaches for community problem-solving.

\section{An HBCU Engages TANF Participants during the Pandemic}

Throughout the COVID-19 pandemic, the University of the District of Columbia's (UDC) Paving Access Trails to Higher Security (PATHS) program placed a major focus on engaging individuals receiving TANF benefits in the District of Columbia. From March 2020 to March 2021, the program staff engaged up to 400 participants in virtual work readiness activities. The diverse group of participants, many who were vulnerable and recognized as a hard-to-reach population, faced multiple barriers to becoming self-sufficient. From March 2020 to March 2021, the UDC PATHS team increased the engagement levels from 32 percent in 2020 to 93 percent in 2021. Several factors contributed to the reversal of engagement levels.

\subsection{The PATHS Program}

The University of the District of Columbia operates the PATHS program in the School of Business and Public Administration. The training and education program was developed for TANF participants in partnership with the District of Columbia Department of Human Services (DHS). The program provides training directly tied to career pathways in conjunction with wraparound case management services to address barriers of each assigned participant.

Program staff administer a battery of career and literacy assessments to identify needs and strengths that form the basis of the participant's personalized plan of action and offers life skills, financial literacy, job readiness and job search support. The PATHS wraparound services incorporate a variety of services and resources within the UDC community, District of Columbia government agencies and community-based partners while addressing and responding to individual needs. The PATHS program provides life skills, transportation farecards, access to an onsite clothing boutique and legal services for participants seeking records expungement.

\subsection{The District of Columbia Department of Human Services}

The District of Columbia Department of Human Services, Economic Services Administration 
is focused on a career pathways approach to workforce development, which connects progressive levels of education, training, support services and credentials for specific occupations in a way that optimizes the progress and success of individuals with varying levels of abilities and needs. The approach works with individuals on long-term planning related to their occupational goals and attainment of self-sufficiency and assists them in meeting financial and family needs while progressing towards those goals (D.C. Department of Human Services, 2020). Career pathways strategies help individuals earn stackable and marketable credentials, engage in further education and employment, and achieve economic success.

The District of Columbia human services agency contracts with the UDC to serve as a TANF Employment and Education Program (TEP) provider. The PATHS program provides case management coaching towards education and employment goals. The coaching services are available to parents and caregivers to set goals for their child (ren) and families.

The District of Columbia Department of Human Services relies on a network of Service Provider partners, and grantees to deliver Education and Occupational Training (EOT), Job Placement (JP), retention services, and family stabilization assistance to non-exempt TANF Customers (D.C. Department of Human Services, 2020).

The mission of the TEP program is to assist TANF participants in enhancing their education and skill levels in preparing for, finding, and retaining unsubsidized employment to ultimately earn family-sustaining incomes and no longer require public assistance. TANF is the central vehicle for helping families who are experiencing economic challenges.

The District human services agency promotes the two-generation model to engage the TANF population. DHS provides cash assistance to individuals and families in need. Families enrolled in the District's TANF program may receive benefits if they are income eligible and have a child in the home. Under the city's TANF program, individuals and families can access to a spectrum of supportive services to meet their needs.

The District's TANF program provides a childcare subsidy to enable parents and/or caregivers to enroll their child(ren) in quality childcare, including before and aftercare. The District of Columbia's Department of Behavioral Health provides counseling to program participants who require access to behavioral and mental health care and substance abuse support. The services are available to individuals and their children.

Tuition assistance is available for TANF program participants. Individuals are eligible to enroll in post-secondary educational programs or professional certificate and/or licensing programs.

Program participants must meet the following requirements for the TANF program:

- Current resident of the District of Columbia.

- Pregnant or responsible for a child under 19 years of age.

- A United States citizen, legal alien and/or permanent resident.

- Meet income requirements based on household size. 
- Complete orientation and assessment through the Office of Work Opportunity (OWO); and

- Development of an Individual Responsibility Plan (IRP).

\section{Two-Generation (2Gen) Approach}

The PATHS Case Managers employed an intentional focus on serving both adults and children together. Case Managers are guided by the Two Generation (2Gen) approach.

Two-generation (2Gen) approaches build family well-being, intentionally and simultaneously, by working with children and the adults in their lives together. The approach recognizes that families come in all different shapes and sizes. Families define themselves (What Is 2Gen?, n.d.).

The 2Gen approach is a poverty alleviation strategy that links together five major components in an intensive, sustained strategy to help lifting families out of poverty. The components of a two-generation model include:

○ Early childhood education.

○ Post-secondary education \& employment pathways.

o Health and well-being.

$\circ$ Economic assets; and

o Social capital. (What is 2Gen?, n.d.)

\subsection{Coaching and Motivational Interviewing}

The PATHS team utilized the 2 Gen approach in their case management coaching to support participants in achieving family, educational and employment goals. Case Managers employed motivational, career-coaching techniques to encourage participants to complete education and occupational training programs. The intent was to prepare participants to enter the workforce. Once the Case Manager deemed the participant was prepared to enter a career pathway, the participant should be deemed employable and ready to receive job placement services.

Motivational interviewing gives participants an opportunity to safely explore the advantages and disadvantages of their goals (Sobell and Sobell, 2010). Coaching promotes supportive relationships as participants seek to achieve their goals (Riccio and Wiseman, 2015). TANF programs report participants are more likely to pursue their interests, meet program requirements and obtain desired employment when coaching and motivational interviewing are used.

One of the most compelling rationales for an integrated two-generation approach to service delivery is the multiplier effects for parents and children. Having both parent and child participate in coordinated services should lead to multiplier effects that could not be achieved when parents and children are enrolled in separate and uncoordinated programs. Spurred on by their children's success, parents may pursue more education and 
obtain employment that offers a living wage.

Further improvement in children's development might follow, for example, in school success and social competence. Ultimately, the benefits of these multiplier effects would accrue not only to the parent or child participating in an intervention, but to the whole family.

\section{Creating a Culture of Engagement}

The PATHS program employed a combination of participant and organization-focused strategies. The participant-centered strategy utilizes case management to encourage participation ( $\mathrm{Vu}$, Anthony and Austin, 2009). The strategy focuses on barriers to employment and other motivational factors that encourage full participation in work-related activities to reduce employment barriers.

Like the participant-focused strategy, the organization-focused strategy supports the goal of employment. The focus, however, is on mobilizing administrative resources to engage participants (Vu, Anthony and Austin, 2009).

\subsection{Participant-Focused Strategies}

Each new TANF participant receives a telephone call when assigned to the PATHS program. Case Managers invite participants to attend an orientation. During this meeting, the Case Manager will provide an introduction, overview of the PATHS training program and the TANF requirements. The Case Manager will conduct an initial assessment and Individual Responsibility Plan with everyone during the Intake process.

Studies on welfare-to-work programs indicate that successful engagement strategies include a high degree of case management that begins with intake (Freedman et al., 2000).

The initial assessment is a one-on-one meeting conducted with the Case Manager.

During the meeting, the Case Manager will identify the individual's strengths as well as barriers toward self-sufficiency. Initial assessments are crucial to identify immediate service needs, determine the capacities of participants to work and identify any special needs (Kauff et al., 2004).

Both the TANF participant and Case Manager develop the Individual Responsibility Plan (IRP). The detailed IRP functions as the agreement between the participant, TEP Provider and DHS. It is an agreement developed jointly by the participant and Case Manager. It serves as the participant's roadmap to securing employment and becoming self-sufficient. The detailed IRP outlines specific steps that the participant consents and commits to taking to address and remove barriers and find and retain employment. It also provides the basis for which any future sanctions would be supported through non-compliance with the IRP on file.

During the initial assessment, the PATHS Case Manager will determine if the participant has any immediate needs, such as food, shelter, medical care, clothing, transportation or childcare. By conducting the initial assessment, Case Managers can identify any immediate needs that might interfere with the individual's participation in work or work-related activities ( $\mathrm{Vu}$, Anthony and Austin, 2009). The Case Manager will then provide the participant with the 
appropriate resources and referrals to address any employment barriers.

\subsection{Organization-focused Strategies}

The PATHS program used broadly defined and flexible program requirements to increase engagement in program activities during the pandemic. Case Managers encouraged participants to engage in $2 \mathrm{Gen}$ and other federally allowable activities such as working or

enrolling in an online training course. Participants were given choices of activities that best matched their needs and interests. A range of options can enable participants to identify and find an activity that fits their interests (Vu, Anthony and Austin, 2009).

\section{Targeted Telehuman Services Delivery}

The PATHS team conducted targeted outreach to each participant via tele human services or virtual human service delivery. Case Managers emailed and/or texted messages to program participants. The tailored message content focused on health and wellness, building social capital, economic security, and financial literacy, early childhood, and postsecondary education. More than 3,000 messages were emailed and/or texted to program participants from March 2020 to March 2021. The outreach included free resources to participants to access virtually and/or in person during the pandemic.

The COVID-19 pandemic disproportionately affected lower income populations (Boserup, McKenney and Elkbuli, 2020). Poverty creates tangible inequities that impact the health, access to education and economic opportunity of people with limited resources (Brenton, 2018). This created an urgency for engaging low-income populations with COVID-19 content and resources (Saul, 2021).

"Low-income populations have some of the lowest levels of adoption of telehealth services, so as healthcare adapts and new innovative care deliver approaches are developed, program staff must ensure the hard-to-reach are included in the shift to virtual care and apply proven strategies for engaging these populations on topics that are important to their health" (McClure, June 19, 2020). Program staff conducted virtual outreach by emailing, calling and texting information about free resources to program participants. The PATHS team tailored emails and texts to each participant's individual needs. Program staff also conducted virtual meetings with participants via virtual platforms such as Microsoft Teams, Zoom, FaceTime and Hangout.

\subsection{Alignment with 2Gen Approaches}

The PATHS team aligned their messaging content with the five components of the two-generation approach. Two-generation approaches target low-income children and parents from the same household, combining parent and child interventions to interrupts the cycle of poverty. The two-generation ( $2 \mathrm{Gen}$ ) approach builds family well-being intentionally and simultaneously by working in the lives of both children and the adults (What is 2Gen?, n.d.). Education, economic supports, social capita, and health and well-being transcend from one generation to another to create a legacy of economic security. The underlying intent is to be inclusive, individualized, integrative and impactful in the approach to engagement (National 


\section{Macrothink \\ Journal of Public Administration and Governance

Parent Teacher Association, 2021).

Examples of the 2Gen content delivered to PATHS participants included the following:

Economic Assets- Addressing financial awareness, housing and transportation needs asset building, housing and public supports, financial capacity and transportation.

o Financial literacy: Free virtual financial literacy and identity fraud courses.

o Savings: Promotion on opening a College Savings Plan.

o Housing: Housing education seminar(s); and

o Obtain documentation: Resources to obtain official government documents.

Health and Well-Being-Behavioral, mental and/or physical health, coverage and access to care, exercise and fitness activities.

o Fitness class-free scheduled programs that supported healthy lifestyles.

o Mental health-Mental Health Outreach for Moms (M.O.M.) virtual activities.

and

○ Food pickup sites and locations.

Social Capital-Strengthening family, peer and community networks (connection to other individuals); coaching strategies.

$\circ$ Free parenting classes.

○ DHS Parent Café; and

○ Legal matters.

Early Childhood Development-Early childhood development, parenting skills, family literacy and health screenings.

○ DCPS virtual parent meetings and fora.

o Free virtual Science, Technology, Engineering and Math (STEM) enrichment programs; and

o College preparation: free virtual college preparation seminars and workshops; Library events: Free book readings and learning activities.

Postsecondary Education- Access to quality education and clear career pathways.

o Training tied to a career pathway-UDC Work Readiness training programs

\section{Communication and Building Relationships}

8.1 Use of Virtual Platforms to Communicate 
During the pandemic, the PATHS team utilized alternatives to in-person human services delivery. Team members communicated with participants virtually and remotely. The breakout is as follows:

- Video Platforms (Microsoft Teams, Zoom, etc.)-5\%

- Telephone $-45 \%$

- Emails- $45 \%$

- Texts-5\%

\subsection{Importance of Respect}

The optimal human services delivery begins by promoting a supportive and trusting relationship between providers and participants. In public health, social distancing, also called physical distancing, refers to the practice of keeping space between yourself and others to reduce the chance of contact with those who knowingly or unknowingly carry an illness (Parino, Zino, Porfiri and Rizzo, 2021). Physical distancing does not mean that one cannot practice courteousness and respect.

Raising your own awareness of a participant's time and needs communicates to them that you respect them. Promptly returning phone calls and emails and holding fast to estimated appointment times are practical ways of communicating respect. This shows clients they can rely on you.

The virtual human service delivery improved the communication between PATHS team members and participants. The team connected with participants by building positive

relationships with them. Case Managers attempted to share and explain information as clearly as possible to guide participants through their IRPs.

\subsection{Use of Data to Track Participation}

Case managers can monitor the work participation status of their caseload on a regular basis. The PATHS Case Managers utilized an electronic database to capture participant participation and engagement rates. This type of monitoring was useful for identifying problems quickly and brainstorming ways to improve the participation rate. The PATHS team administered targeted case management services to interest participants who were not actively engaged. When these tools are available online, case managers can monitor the work participation status of their caseload on a regular basis (Pavetti et al, 2008).

\subsection{Regular Communication}

The frequency of the outreach also contributed to the increased engagement. The PATHS team members telephoned, emailed and/or texted two to three times per week. Case

Managers conducted follow-up telephone calls after each communication. The preferred choice of communication by both program staff and participants was telephone. Telephone communication was utilized $45 \%$ of the time. 


\section{Ml Macrothink}

Journal of Public Administration and Governance

ISSN 2161-7104

2021, Vol. 11, No. 3

Team members emailed participants, at a minimum of $45 \%$ of the time, to communicate with participants. Case Managers texted participants 5\% of the time. Texting was a secondary communication channel to communicate with participants.

The PATHS team members utilized various methods of verbal, written and virtual platforms to communicate and engage with participants. This included telephone calls, emails, texts, letters and Microsoft Teams and Zoom. The PATHS team established clear communication channels between participants and team members. Participants had access to each team member's email address and telephone number. This provided both the team member and participant with direct access to each other.

\subsection{Creating Culturally Diverse Messaging}

The messaging content was culturally diverse and specific to the target population served by the PATHS program. The content focused on resources in each of the program participant's neighborhoods and/or which were accessible to participants.

There are potentially smaller and diverse audiences in a "low-income population." This is a decidedly un-monolithic group. The diversity among individuals with low socioeconomic

backgrounds is staggering (Brenton, 2018). The PATHS program participants were urban residents of color and/or immigrants and long-time residents dependent on government assistance.

The similarities likely ended there (Brenton, 2018). Each of them had different needs. Each of these subgroups require different strategies and tactics to become self-sufficient. The PATHS team tailored resources to meet each participant's needs and goals as identified in their respective IRPs.

\section{Access to Technology}

The COVID-19 pandemic compelled the PATHS team to transition to virtual human service delivery options. In-person activities were no longer a reality. Virtual platforms, although used by many, were not an option for all participants. Program participants faced broadband access, hardware (i.e., laptops, tablets or computer) and knowledge deficits. One-third of the students PATHS participants lacked access to technology at home, devices and/or the necessary digital literacy skills.

There were participants with only a smartphone and no data plan. There were other participants who had multiple devices and Internet access. This disparity in digital access prompted the PATHS program to partner with DHS and a local community-based program to distribute laptops to participants who did not have a laptop or tablet.

\subsection{Digital Inclusion and Equity}

According to new research, (Digital Inclusion and Equity: Washington, D.C. Fast Facts, 2021), 55\% of households in Ward 7 of Washington, D.C. do not have broadband Internet access. Fifty-two percent of households in Ward 8 do not have broadband Internet access. 


\section{$\triangle 1$ Macrothink}

Journal of Public Administration and Governance

ISSN 2161-7104

2021, Vol. 11, No. 3

Approximately $37 \%$ of PATHS participants reside in Ward 8 . A total of $21 \%$ of PATHS participants reside in Ward 7.

During the intake process, none of the PATHS participants residing in both Wards 7 and 8 reported a need for broadband Internet access. Less than five percent of participants in both Wards 7 and 8 reported a need for a laptop and/or tablet.

In response, the PATHS developed partnerships to ensure that the underserved population was not excluded from the digital economy. The COVID-19 pandemic presented a barrier for many PATHS participants without access to the Internet or technology. The PATHS program partnered with a community-based organization to obtain laptop devices. DHS also provided laptops for some individuals who did not have a laptop and were interested in improving their digital skills.

To be competitive in the job market, applicants must have digital skills to master the most fundamental basic competencies. COVID-19 was like pouring gasoline on the digital transformation (Ray, 2020). The pandemic ignited the digital transformation and magnified the global workforce. A third of new jobs created in the United States have been in occupations that did not previously exist. It is estimated that 1.1 billion jobs may be transformed by 2030 (Manyika, 2017).

Equitable access to technology refers to all students having access to technology and information regardless of their ethnicity, socio-economic status, age, physical ability or any other quality. Access to technology is not only integral for participants to learn, but also a fundamental component in assisting students with acquiring the knowledge and skills they need to become digitally savvy citizens. A lack of equitable access to technology and information deprives students of learning experiences and can even limit their opportunities, especially after graduation. For many, this inequity was further exacerbated by the virtual learning environment this year (GoGuardian, 2020).

\subsection{Digital Literacy}

The PATHS team engaged 100 participants to enroll in Digital Literacy and Contact Tracing courses. To function in today's virtual environments, individuals need foundational computer skills to access and consume digital content, create it, and share it. Recent data indicates that as technology evolves, so will the requisite skills needed, and continuing training to remain digitally literate ((Digital Inclusion and Equity: Washington, D.C. Fast Facts, 2021).

Upon completion of the course, students earned three certifications. They included the following certifications:

- Northstar Digital Literacy Essential Computer Skills.

- Northstar Digital Literacy Essential Software Skills; and

- Northstar Digital Literacy Using Technology in Daily Life. 
The Northstar Digital Literacy program was utilized to provide the basic skills needed to use a computer and the Internet in daily life, employment and higher education. PATHS participants completed the program remotely. Students learned basic computer and software skills.

Workforce development and digital equity are closely related. One-third of American workers lack the digital skills required for work, school, and life. Access to technology is more than just providing devices and connectivity to students. Access to technology and digital literacy delivers real life impacts on the lives of American workers.

\section{Participant Results}

\subsection{Online Training Certifications}

From March 2020 to September 2021, the PATHS program offered online training in Entrepreneurship and certifications for the Community Health Worker and Contact Tracing, and Digital Literacy. The PATHS program offered job-driven training that was directly tied to career pathways. This was important to connect both the TANF and workforce systems. Job-driven training approaches, including career pathways, can provide participants with skills and resources to obtain and retain employment in promising occupations (Administration for Children and Families, 2015).

The virtual classes and human service delivery improved workforce support for PATHS participants. The online courses provided participants with a balanced family and training schedule and increased participant engagement. The online training classes were offered during afterschool hours and provided parents time to focus on their classes.

\subsection{Impact of Childcare and Engagement in 2Gen Activities}

Previous studies indicated that childcare and transportation were consistent barriers to participant engagement in TANF program activities (Kauff et al., 2004). Childcare referrals plummeted during the pandemic. Parents were able to remain at home and care for their children. Approximately 194 parents, out of 241, engaged in early childhood activities for and with their children.

PATHS program participants engaged in the following 2Gen activities:

- Early Childhood Education-66\% (194 individuals).

- Economic assets - 4\% (12 individuals).

- Health and wellness - 28\% (75 individuals).

- Postsecondary education - 11\% (33 individuals); and

- GED/High school diploma - 6\% (19 individuals)

\subsection{Engagement in Postsecondary Education}

A total of 33 individuals enrolled in five different institutions of higher learning to advance their education. There were 75 participants engaged in health and wellness activities. 
Nineteen individuals completed and/or earned high school diploma and/or general equivalency degree (GED).

\subsection{Program Demographics}

Approximately $95 \%$ of the PATHS participants were female and African American. Most of the PATHS participants represented single-headed households. Fifty percent of the PATHS participants resided in Wards 7 (21\%) and Ward 8 (37\%) of Washington, D.C. None of the PATHS participants residing in Ward 7 reported a lack of broadband Internet access.

Less than 10 PATHS participants in Ward 7 reported a lack of access to a laptop and/or tablet.

According to the Census, $26.3 \%$ of the population in Ward 7 lives below the poverty line. The median household income in Ward 7 is $\$ 45,318$. This is about half of the amount of the medium household income in the District of Columbia $\$ 86,420.85 .8 \%$ of the residents in Ward 7 have graduated from high school or higher (Ward 7, DC Profile Data, 2019).

Of the $37 \%$ of PATHS participants residing in Ward 8 , all have reported having broadband Internet access. Less than 10 reported a need for a laptop and/or tablet.

According to the Census, $32.9 \%$ of the population in Ward 8 lives below the poverty line. The median household income in Ward 8 is $\$ 35,245$. This is nearly two-fifths of the median household income in Washington, D.C. $86 . \%$ of the residents in Ward 8 have graduated from high school or higher (Ward 8, DC Profile Data, 2019).

At the beginning of the pandemic, many TANF participants, largely female, faced barriers to employment, including low-wages, lack of affordable childcare, COVID and skills deficits. As employers seek to resume business as usual, many are facing labor shortages. Despite the unemployment numbers being in the millions, there are 8.1 million vacancies (Filipovic, 2021). The vacancies are highly concentrated among America's low-wage workforce. The key industries include restaurants, warehouses, manufacturers and services. Now is the time for employers to consider the TANF population as a viable pool to fill the vacancies. Employers will need to consider additional flexible work schedules, on-the-job training and virtual employment opportunities to recruit and address workforce shortages.

\section{Lessons Learned}

As the world faces the 'new normal' post-COVID, there are important lessons that should be implemented post pandemic to engage the TANF population.

1. Historically black colleges and universities (HBCUs) must collaborate to serve our most vulnerable populations.

2. Human service agencies must prioritize training on culturally competent care. Community health workers can serve as a resource to assist participants in navigating the human services delivery system. 
3. Community-based organizations can assist Case Managers with building relationships and trust through advisory councils, or community board memberships.

4. It is essential that agencies continue to engage individuals online and by telephone, to address their critical needs.

5. The delivery of tele human services reduced travel time, childcare costs and time and reduced barriers to services for parenting support. The virtual human service delivery will continue to provide benefits to both employers and vulnerable populations.

6. As technology continues to reshape the economies around the world, individuals must acquire the new digital skills to transform themselves in the new digital reality.

7. COVID-19 has increased the awareness for the need for digital skills for all industries. Technology touches every employee now. "Every job is in some way a digital job," agrees Naria Santa Lucia, Microsoft Philanthropies' General Manager of employability skills. "Even if you're not working in the tech sector, everyone needs to have the basics of digital fluency (Ray, 2020).”

8. Hard-to-employ and underemployed parents are a viable option for businesses with growing workforce shortages to sustain economic growth and competitiveness.

9. States must examine industry workforce needs to encourage TANF participants to pursue a sustainable career pathway and build a stronger economy.

\section{References}

Administration for Children and Families. (2015). Systems to Family Stability National Policy Academy Overview. U.S. Department of Health and Human Services. https://www.acf.hhs.gov/sites/default/files/documents/ofa/systems_to_family_stability_acade my_overview.pdf

Benton, A., Tschantz, J., Vandenburg, A., Waters, A., \& Winston, P. (2021, February). Virtual Human Services for Different Populations. U.S. Department of Health and Human Services Office of the Assistant Secretary for Planning and Evaluation. https://aspe.hhs.gov/sites/default/files/migrated_legacy_files/199061/VHS-Different-Populati ons.pdf\#: :text=While\%20virtual\%20human\%20services\%20thus\%20offer\%20a\%20range,u rban\%20area\%20that $\% 20$ lacks\%20accommodate\%20with\%20virtual\%20visits.

Boserup, B., McKenney, M., \& Elkbuli, A. (2020). Disproportional impact of COVID-19 pandemic on racial and ethnic minorities. American Surgeon, 86(12), 1615-1622. https://doi.org/10.1177/0003134820973356

Brenton, K. (2018, November 12). Improving outreach to low-income populations. SE2 Communications.

https://se2changeforgood.com/2018/11/12/improving-outreach-to-low-income-populations/

Carter, C. (2020, July 22). Temporary Assistance for Needy Families Program Instruction. U.S. Department of Health and Human Services Administration for Children and Families 
Office

of

Family

Assistance.

https://www.hhs.gov/guidance/sites/default/files/hhs-guidance-documents//tanf_program_inst sruction_final722202.pdf

Digital inclusion and equity: Washington, D.C. fast facts. (2021). Center for Nonprofit Housing and Economic Development. https://cnhed.org/wp-content/uploads/2021/05/Digital-Inclusion-and-Equity-One-Pager1.pdf

District of Columbia Department of Human Services. (n.d.). TANF for District Families. D.C. Department of Human Services. Retrieved June 4, 2021, from https://dhs.dc.gov/service/tanf-district-families

District of Columbia Department of Human Services. (2020). D. C. Department of Human Services (DHS) Primary and Secondary Service Provider Manual. D.C. Department of Human Services.

Falk, G., \& Landers, P. (2021, March). Temporary Assistance for Needy Families and ProposednCOVID-19 Pandemic Economic Relief: In Brief. Congressional Research Service. https://crsreports.congress.gov/product/pdf/R/R46692

Filipovic, J. (2021, June 2). The real reason employers cannot hire enough workers. CNN. https://www.cnn.com/2021/06/01/opinions/covid-workers-labor-shortage-pandemic-benefitsfilipovic/index.html

Freedman, S., Friedlander, D., Hamilton, G., Rock, J., Mitchell, M., \& Nudelman, J. (2000, June). National Evaluation of Welfare-to-Work Strategies: Evaluating Alternative Welfare-to-Work Approaches: Two-Year Impacts for Eleven Programs: Executive Summary.

Manpower Demonstration Research Corporation. https://aspe.hhs.gov/reports/national-evaluation-welfare-work-strategies-evaluating-alternativ e-welfare-work-approaches-two-year

GoGuardian. (2020, September 2). What it means to have equitable access to technology for today's students and educators. https://www.goguardian.com/blog/technology/equitable-access-to-technology/\#: :text=Equit able $\% 20$ access $\% 20$ to $\% 20$ technology $\% 20$ refers $\% 20$ to $\% 20$ all $\% 20$ students,status $\% 2 \mathrm{C} \% 20$ age $\% 2 \mathrm{C} \% 20$ physical\%20ability\%2C\%20or\%20any\%20other\%20quality

Kauff, J., Derr, M. K., \& Pavetti, L. (2004, August). A study of work participation and full engagement strategies. Mathematica Policy Research, Inc. https://aspe.hhs.gov/reports/study-work-participation-full-engagement-strategies-1

Manyika, J. (2017, May). Technology, jobs and the future of work. McKinsey Global Institute. https://www.mckinsey.com/featured-insights/employment-and-growth/technology-jobs-and-t he-future-of-work

McClure, B. (2020, June 19). The importance of tailored telehealth engagement for low-income populations. MPulse Mobile. https://mpulsemobile.com/2020/06/the-importance tailored-telehealth-engagement-for-lowincome-populations/ 
Meyer, L., \& Pavetti, L. (2021, January). TANF Improvements Needed to Help Parents Find Better Work and Benefit from an Equitable Recovery. Center for Budget and Policy Priorities. https://www.cbpp.org/research/family-income-support/tanf-improvements-neededto-help-par ents-find-better-work-and

National Parent Teacher Association. (2021, June 1). Tools to Turn Your Commitment to Diversity, Equity \& Inclusion into Action [Video]. YouTube. https://www.youtube.com/watch?v=5RBOvxcsq-Y

OFA publishes guidance on the implications of the COVID-19 pandemic for the TANF program. (2020, March 24). U.S. Department of Health and Human Services Administration for Children and Families. https://www.acf.hhs.gov/ofa/news/ofa-publishes-guidance-implications-covid-19-pandemic-t anf-program

Parino, F., Zino, L., Porfiri, M., \& Rizzo, A. (2021). Modelling and predicting the effect of social distancing and travel restrictions on COVID-19 spreading. Journal of the Royal Society Interface, 18(175), 1-10. https://doi.org/10.1098/rsif.2020.0875

Pavetti, L., Kauff, J., Derr, M., Maxx, J., Person, A., \& Kirby, G. (2008, December). Strategies for increasing TANF work participation rates (No. 5). Mathematica Policy Research, Inc. https://aspe.hhs.gov/reports/strategies-increasing-tanf-work-participation-rates-summary-repo rt-0

Ray, S. (2020, November 16). Free online digital skills courses revive hope and careers formillions amid the pandemic. Microsoft. https://news.microsoft.com/features/free-online-digital-skills-courses-revive-hope-and-career s-for-millions-amid-the-pandemic/

Riccio, J., \& Wiseman, M. (2015, November). The "FSS- $X$ ” demonstration: Combining an executive skills coaching model with financial incentives to improve economic mobility for families with housing see more at: https://selfsufficiencyresearch.org/content/fss-x-demonstration-combining-executive-skills-co aching-model-financial-incentives-improve (Corporation, Ed.). Manpower Demonstration Research Corporation.

Saul, A. (2021, April 2). Outreach to vulnerable populations during the COVID-19 pandemic. Social Security Administration. https://blog.ssa.gov/outreach-to-vulnerable-populations-during-the-covid-19-pandemic/

Sobell, L. C., \& Sobell, M. (2008). Motivational interviewing strategies and techniques: Rationales and examples. Nova Southeastern University. https://www.esrdnetwork.org/sites/default/files/MI_rationale_techniques.pdf

Targeted communication: The key to effective stakeholder engagement. (2016). Procedia-Social and Behavioral Sciences, 226, 431-438. https://doi.org/10.1016/j.sbspro.2016.06.208 


\section{Macrothink}

Journal of Public Administration and Governance ISSN 2161-7104 2021, Vol. 11, No. 3

Vu, C., Anthony, E. K., \& Austin, M. J. (2018). Strategies for engaging adults in welfare-to-work activities. Families in Society: The Journal of Contemporary Social Services, 90(4), 359-366. https://doi.org/10.1606/1044-3894.3929

Ward 7, DC Profile data. (2019). Census Reporter. https://censusreporter.org/profiles/61000US11007-ward-7-dc/

Ward 8, DC Profile data. (2019). Census Reporter. https://censusreporter.org/profiles/61000US11008-ward-8-dc/

What is 2Gen? (n.d.). Ascend at the Aspen Institute. Retrieved March 20, 2020, from https://ascend.aspeninstitute.org/two-generation/what-is-2gen/

\section{Copyright Disclaimer}

Copyright for this article is retained by the author(s), with first publication rights granted to the journal.

This is an open-access article distributed under the terms and conditions of the Creative Commons Attribution license (http://creativecommons.org/licenses/by/4.0/). 